\title{
A persistência das desigualdades raciais no sistema de justiça criminal dos $\mathbf{E U A}^{1}$
}

\author{
The persistence of racial inequalities in the US criminal justice \\ system in USA
}

George E. Bisharat ${ }^{2}$

\section{Resumo:}

Este trabalho trata da persistência da desigualdade racial no sistema de justiça norte-americano e busca discutir as possíveis explicações para este fenômeno. Também são discutidas as consequências desta realidade persistente e, ao final, são apresentadas possíveis maneiras de conseguir avanços.

Palavras-chave: EUA, desigualdade racial, sistema de justiça criminal

\begin{abstract}
:
This paper deals with the persistence of racial inequality in the US justice system and seeks to discuss possible explanations for this phenomenon. The consequences of this persistent reality are also discussed, and in the end possible ways of achieving changes are presented as well.
\end{abstract}

Keywords: USA, racial inequalities, criminal justice system

\footnotetext{
${ }^{1}$ Tradução de Luiza Aragon, revisão técnica de Roberto Kant de Lima.

${ }^{2} \mathrm{O}$ autor é Professor of Law, Hastings College of the Law, Univerty of California at San Francisco (UCSF) e consultor internacional do Instituto Nacional de Ciência e Tecnologia- Instituto de Estudos Comparados em Administração de Conflitos (INCT-InEAC - www.ineac.uff.br).
} 


\section{Introdução}

Este artigo trata da frustrante persistência da desigualdade racial no sistema de justiça americano - um problema que tem me preocupado desde a juventude. Era impossível crescer nos Estados Unidos, na época em que eu cresci, e não estar ciente deste assunto. Quando eu tinha dez anos de idade e vivia no sul da Califórnia, aconteceram rebeliõesem Watts, um bairro predominantemente afro-americano de Los Angeles, iniciadasa partir da abordagem policial de um homem afro-americano. Periodicamente, ao longo dos anos, nós tivemos - a cada cinco ou dez anos, quase de modo cronometrado - grandes inquietações civis sobre percepções, senão sobre realidades, de tratamento desigual pela polícia no caso de pessoas de cor. Mais recentemente, tivemos manifestações em Ferguson, Missouri, após o assassinato de Michael Brown e em Charlotte, Carolina do Norte, em resposta à morte a tiros de Keith Lamont Scott, como também protestos diários ao redor do país pelas mortes de muitos outros homens negros nas mãos da polícia.

Para além das desigualdades que eu testemunhei simplesmente pelo fato de ser um cidadão americano, a experiência trabalhando como defensor público me perturbou profundamente (defensores públicos são advogados criminais de defesa, designados pelos tribunais para representar acusados indigentes). A realidade da desigualdade no sistema de justiça criminal se destacou para mim quando comecei o treinamento para a defesa em casos de crimes graves. Eu tinha estado no escritório da Defensoria Pública em São Francisco por aproximadamente um ano trabalhando na defesa de casos de delitos leves e, quando adquiri experiência suficiente, o escritório me promoveu à atuação em casos decrimes graves. Meu primeiro exercício de preparação para defender acusados destes crimes foi simplesmente seguir e observar um advogado mais experiente por vários dias. Certa vez, acompanhei as audiências de custódia $^{3}$ agendadas para o Tribunal de Justiça de São Francisco. Assisti entre 22 e 25 aparições e todos os acusados eram afro-americanos! Isto numa cidade liberal, progressista com uma

\footnotetext{
${ }^{3}$ [RT $\}$ A audiência de custódia (arraignment) acontece quando uma pessoa que foi presa faz sua primeira aparição diante do tribunal.
} 
população afro-americana que era, àquela época, aproximadamente onze por cento ${ }^{4}$. Esta é uma cidade que se orgulha de exercer tolerância e aceitação. Isto desafia a lógica de que onze por cento da população possa ser responsável por $100 \%$ dos delitos.

Então, como pode ser assim? Como poderíamos ter esta desigualdade nítida, particularmente em São Francisco, este bastião de valores progressistas?

Infelizmente, em quase qualquer lugar onde você vá em meu grande país, há evidências substanciais para mostrar que as minorias raciais sofrem discriminação em todos os estágios de seus encontros com a polícia e com o sistema de justiça criminal. Quando as pessoas de cor, normalmente afro-americanos e latinos, são vigiadas, elas serão mais provavelmente paradas. Quando são paradas, é mais provável que elas sejam revistadas. Quando elas são revistadas, têm maior probabilidade de serem presas. Uma vez presas, elas têm maiores chances de serem formalmente acusadas e, sobretudo, por crimes de maior gravidade. As evidências de discriminação atravessam cada fase do processo criminal, inclusive, até a sanção máxima, de sentença de morte.

Este artigo tem como objetivo fazer seis coisas. Primeiro, eu vou expor alguns fatos básicos sobre nosso sistema de justiça criminal, oferecendo, assim, um contexto para discutir problemas a partir dos quais se ramificam as desigualdades raciais neste sistema. Em seguida, vou apresentar evidências de que as desigualdades raciais, as quais historicamente afligiram o sistema de justiça criminal nos Estados Unidos, continuam a existir no presente. Apesar disto não ser uma declaração controversa, se trata de um paradoxo na era da "cegueira de cor", a saber, época em que o racismo é publicamente criticado e rejeitado. As próximas três seções vão considerar possíveis explicações para este fenômeno, ou para esta aparência, de desigualdade racial. A primeira delas afirma que a pobreza é, de fato, um problema real; a seguinte propõe que nós estamos, na verdade, vendo as consequências do que chamamos de nossa "Guerra às Drogas"; e, finalmente, a terceira considera a possibilidade de que o encarceramento em massa é, como alguns autores o chamaram, "o novo Jim Crow", ou seja, um sistema que sustenta a

\footnotetext{
${ }^{4}$ A população negra de São Francisco tem diminuído gradativamente desde aquela época para alcançar seu nível atual, de aproximadamente seis por cento. Fonte: United States Census, Population Estimates for San Francisco County, California as of July 1, 2017.

https://www.census.gov/quickfacts/fact/table/sanfranciscocountycalifornia/PST045217\#viewtop

${ }^{5}$ Em inglês, color blindness
}

Revista Juris Poiesis - Rio de Janeiro. Vol.21- ${ }^{\circ} 27,2018$, pg.256 - 282. ISSN 2448-0517 Rio de Janeiro, 31 de dezembro de 2018. 
supremacia branca. Estas explicações se sobrepõem e não são mutuamente excludentes, e apenas porque uma delas pode ser, em parte, verdadeira, isso não significa que as outras não são também verdadeiras em alguma medida. De fato, cada uma destas explicações possui um núcleo verdadeiro, mas também possivelmente algumas fraquezas. Em última análise, no entanto, minha conclusão é que a terceira e última destas explicações é a mais persuasiva, mesmo que seja a mais perturbadora. $\mathrm{Na}$ sexta e última parte, eu discutirei as consequências desta realidade persistente da desigualdade racial e farei referência a algumas possíveis maneiras de conseguir avanços.

\section{Fatos Básicos sobre o Sistema de Jurídico dos EUA}

Nós temos um sistema jurídico federal nos Estados Unidos onde todos os cinquenta estados possuem, separadamente, soberania. Os estados reservam para si quaisquer poderes não explicitamente delegados ao nosso governo nacional. Um de tais poderes, reservado aos estados, é o "poder de polícia", o qual abrange o poder de definir e processar crimes. Nós temos um sistema federal de justiça criminal, mas existem relativamente poucos crimes federais. Portanto, a vasta maioria das persecuções criminais são conduzidas a nível estadual ${ }^{6}$.

Enquanto os sistemas estaduais de justiça criminal variam em alguma medida, as variações entre os estados não são grandes, ao menos não comparadas às diferenças entre, por exemplo, o sistema estadunidense e o brasileiro. Como ilustração de diferença entre eles, podemos ver que, enquanto todos os cinquenta estados e o sistema federal seguem o sistema de Trial by Jury, 39 deles permitem que um corpo de jurados possua menos de doze pessoas ${ }^{7}$. Em alguns estados, o número de jurados pode chegar a apenas seis pessoas, para julgar delitos leves ${ }^{8}$ E 48 estados

6 Ver Federal Justice Statistics, Bureau of Justice Statistics, 2014, (estudo mais recente) https://www.bjs.gov/content/pub/pdf/fjs1314_sum.pdfe comparar com Prosecutors in State Courts, Bureau of Justice Statistics, 2007, (estudo mais recente) https://www.bjs.gov/content/pub/pdf/psc07st.pdf

7 Jan Hoffman, Editorial, The Nation; Why a Jury Can Be 12, Even 6, but Not 5, N.Y. TIMES(June 11, 1995), https://www.nytimes.com/1995/06/11/weekinreview/the-nation-why-a-jury-can-be-12-even-6-but-not-5.html; verWilliams v. Florida, 399 U.S. 78 (1970).

${ }^{8}$ Delitos leves geralmente são punidos com não mais que dois anos de cadeia. 
requerem unanimidade entre os jurados para uma condenação, enquanto dois não o exigem ${ }^{9}$. Existem muitas outras diferenças entre os procedimentos judiciais de cada estado, nesta escala. Por este motivo, não é um abuso falar generalizadamente sobre um "sistema de justiça criminal dos Estados Unidos".

Uma das maiores razões para similaridades em jurisdições diferentes foi a passagem da $14^{\mathrm{a}}$ Ementa da Constituição americana após a Guerra Civil, a qual sustenta que governos estaduais não poderiam privar os cidadãos da vida, da liberdade, ou da busca pela felicidade sem a passagem por um processo judicial ${ }^{10}$, o que deu início ao processo gradual de garantia, na prática, dos direitos individuais instituído no Bill of Rights ${ }^{11}$. Dessa forma, os estados foram forçados a atuar através das mesmas restrições processuais que se aplicavam ao sistema federal. O efeito foi estabelecer um patamar mínimo de proteções para os réus, do qual os estados não poderiam abdicar. Eles estavam livres para prover maiores proteções, mas não menos, e consequentemente, a $14^{\mathrm{a}}$ Emenda promoveu um nível nacional de uniformidade no processo criminal dos Estados Unidos.

Uma importante cláusula da $14^{\mathrm{a}}$ Emenda é a Equal Protection Clause. Esta cláusula estabelece que os estados não podem discriminar os cidadãos em diferentes categorias sem uma razão convincente e legítima. A raça raramente é uma categoria legítima para discriminação. Em teoria, a $14^{\mathrm{a}}$ Emenda deveria prover uma poderosa ferramenta para a defesa contra a discriminação racial no sistema de justiça criminal. Porém, isso não aconteceu, devido à jurisprudência da nossa Suprema Corte sobre a 14 ${ }^{\mathrm{a}}$ Emenda, a qual demandava "intenção discriminatória" ${ }^{12}$, algo extremamente difícil de $\operatorname{provar}^{13}$. Não é suficiente, de acordo com a

\footnotetext{
${ }^{9}$ Non-Unanimous Jury Convictions Violates Equal Protection Clause, ACLU OREGON (December, 15 2016), https://www.aclu-or.org/en/cases/non-unanimous-jury-convictions-violate-equal-protection-clause; vertambémApodaca v. Oregon, 406 U.S. 404 (1972); and Johnson v. Louisiana, 406 U.S. 356 (1972).

${ }^{10}$ [RT] Sobre as diferenças entre o due process of law dos EUA e o processo judicial brasileiro, ver KANT DE LIMA, Roberto. Polícia, justiça e sociedade no brasil: uma abordagem comparativa dos modelos de administração de conflitos no espaço público.. Revista de Sociologia e Política, Curitiba - Paraná, v. 1, n.13, p. 2338, 1999; FERREIRA, Marco Aurélio Gonçalves. O devido processo legal: um estudo comparado. Rio de Janeiro: Lúmen Juris, 2004..

${ }^{11}$ [RT\} O Bill of Rights, nos EUA é composto pelas dez primeiras emendas da Constituição dos Estados Unidos. ${ }^{12}[\mathrm{RT}]$ Discriminatory intent

${ }^{13}$ Ver Washington v. Davis, 426 U.S. 229 (1976); ver também Village of Arlington Heights v. Metropolitan Housing Development Corp., 429 U.S. 252 (1977).
} 
Suprema Corte, que é o último árbitro do significado constitucional, que a lei tenha impacto discriminatório, se a intenção de causar este impacto não existe. Na prática, a $14^{\mathrm{a}}$ Emenda se mostrou largamente ineficaz para desafiar as desigualdades do sistema de justiça, uma vez que as evidências de intenção discriminatória são tão difíceis de provar.

\section{Evidências de que as Desigualdades Raciais Continuam a Existir}

Não é controverso afirmar que o sistema de justiça criminal funcionou como uma ferramenta de dominação racial durante a formação dos Estados Unidos, mais óbvia e diretamente durante o período da escravidão, a qual apenas formalmente acabou na metade do século XIX, em seguida e como uma consequência do final da nossa Guerra Civil. Antes deste período, nós tínhamos códigos escravistas separados, de natureza draconiana, os quais autorizavam terríveis punições, baseadas em ofensas absolutamente triviais, as quais geralmente consagravam na lei uma variedade de formas de desigualdade. ${ }^{14}$ Também não é controverso dizer que estas desigualdades persistiram, apesar de tomar diferentes formas, na Era Jim Crow.

O termo "Jim Crow" vem de uma canção popular da metade do século XIX, a qual essencialmente ridiculariza afro-americanos como estúpidos, incompetentes e indignos de cidadania $^{15}$. A Era Jim Crow levou o nome da música e se refere a um conjunto de leis e práticas geralmente usadas por governos estaduais, principalmente no Sul dos Estados Unidos, mas não apenas lá, para manter privilégios após a Guerra Civil. Isso foi possível através de segregação na habitação, de restrições eleitorais e através de um tratamento altamente desigual no direito penal. Tudo isso aconteceu apesar da passagem, pós-Guerra Civil, da 14 ${ }^{\mathrm{a}}$ Ementa da nossa Constituição, a qual, como mencionamos previamente, determinava que os estados deveriam prover proteção igualitária para as pessoas e não poderiam exercer discriminação com base na raça.

\footnotetext{
${ }^{14}$ Ver, por exemplo, JD Thomas, Law of Slavery in the State of Louisiana, ACCESSIBLE ARCHIVES (August 24, 2011), http://www.accessible-archives.com/2011/08/law-of-slavery-in-the-state-of-louisiana/; vertambém Paul Finkelman, editor, Statutes on Slavery: The Pamphlet Literature (2007).

${ }^{15}$ Thomas D. Rice, The Original Jim Crow, New York, (1832), https://en.wikisource.org/wiki/The Original_Jim_Crow
} 
O nível de violência e brutalidade visto contra os afro-americanos em todas as facetas da sociedade neste período foi horrível. Tínhamos um vigilantismo, o qual se manifestava através dos cidadãos que exerciam violência contra os afro-americanos sem punição, incluindo milhares de linchamentos. Este foi o auge da notória Ku Klux Klan, a qual aterrorizava as comunidades afro-americanas como forma de manter sua subserviência. O período de Jim Crow não acabou verdadeiramente até a metade do século XX, com uma série de importantes decisões da Suprema Corte dos Estados Unidos, e com a passagem do Civil Rights Act e do Voting Rights Act. ${ }^{16}$

Pelo menos até recentemente, havia uma percepção bastante ampla nos Estados Unidos de que, pouco a pouco, desde a Era Jim Crow, nós havíamos virado a página enquanto nação. O racismo explícito é totalmente inaceitável numa "sociedade polida"17. Por exemplo, a palavra hoje mais cercada de tabu entre os estadunidenses ricos e educados é "nigger" (no entanto, ainda é usada como expressão popular, particularmente entre brancos mais pobres) ${ }^{18}$. Quem elabora políticas públicas deve evitá-la, assim como quaisquer líderes, estejam eles no governo ou no mundo empresarial, sendo este motivo para demissão (por iniciativa própria ou não). Para muitas pessoas, a percepção da igualdade racial foi exemplificada, não apenas uma vez, mas duas vezes, na eleição de um homem afro-americano ${ }^{19}$ - Barak Obama - para presidente dos Estados Unidos. Que símbolo mais visível da era da cegueira de cor poderia haver?

A principal frente na contínua luta por direitos civis, nas últimas quatro décadas, tem sido as ações afirmativas, com o esforço de promover opções e oportunidades para afro-americanos e outras pessoas de cor em educação, emprego, habitação e similares ${ }^{20}$. No entanto, para qualquer um que de fato preste atenção, os problemas da desigualdade racial no sistema de justiça criminal nunca desapareceram.

\footnotetext{
${ }^{16}$ Ver Michelle Alexander, The New Jim Crow, páginas 35-40, THE New Press (2012); (RT) traduzido no Brasil como A Nova Segregação: racismo e encarceramento em massa. São Paulo, Boitempo, 2017.

${ }^{17}$ No nível das elites.

${ }^{18}$ Ver, por exemplo, Laura Ly, Oberlin College Cancels Classes to Address Racial Incidents, CNN (March 5, 2013) https://www.cnn.com/2013/03/04/us/ohio-oberlin-hate-incidents/index.html (A Universidade de Ohio, na Faculdade de Oberlin, precisou cancelar as aulas com o objetivo de reunir professores e estudantes para fazer uma declaração sobre os valores da inclusão, do respeito aos outros, e de uma fé forte e persistente no valor de cada indivíduo, após ocorrerem quinze eventos relacionados a ódio dentro do campus).

${ }^{19} \mathrm{Na}$ verdade, sua origem racial é mista, mas nos Estados Unidos o princípio de "uma gota de sangue" prevalece, o que significa que ele é percebido como negro pela sociedade.

${ }^{20}$ What is Affirmative Action?, ACLU, https://www.aclu.org/other/what-affirmative-action
} 
A evidência é irrefutável de que pessoas de cor sofreram as consequências da aplicação da justiça criminal de uma forma desproporcional. Por exemplo, em 2011, o Departamento de Polícia de Nova Iorque abordou e revistou pessoas 685.724 vezes: 350.743 pessoas eram negras,

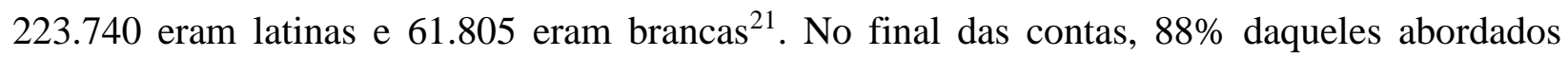
eram inocentes de qualquer crime, o que significa que milhares de pessoas de cor inocentes eram sujeitas a medidas policiais invasivas sem um bom motivo. Muito mais poderia ser dito aqui sobre discriminação em outros estágios dos encontros dos cidadãos com a força policial e o sistema judicial. Entretanto, vou direto ao ponto: as taxas de encarceramento, o destino final no sistema de justiça dos EUA.

Nos Estados Unidos, hoje, sessenta por cento de todos os encarcerados são pessoas de $\operatorname{cor}^{22}$, enquanto elas constituem apenas 35 por cento da população ${ }^{23}$. Talvez o fato de que existem mais latinos no sistema hoje do que no passado indique uma mudança na desproporcionalidade que afeta os afro-americanos, no entanto, a taxa de encarceramento de negros é ainda 5,1 vezes mais alta que a de brancos ${ }^{24}$. Uma em cada quatro crianças negras atualmente tem um de seus pais, normalmente o pai, na cadeia ${ }^{25}$. A taxa de encarceramento de latinos é 1,4 vezes maior que a de brancos ${ }^{26}$. Portanto, a questão é: como explicamos o fato de que minorias raciais são tão desproporcionalmente colocadas na cadeia numa era da cegueira de cor?

\section{Primeira Hipótese: Pobreza, ou Classe Social, é o Verdadeiro Problema}

\footnotetext{
${ }^{21}$ Annual Stop-And-Frisk Numbers: New York, ACLU (2002-2017), https://www.nyclu.org/en/stop-and-frisk-data ${ }^{22}$ Especificamente, afro-americanos e latinos.

${ }^{23}$ Criminal Justice Facts, THE SENTENCING PROJECT, (2016), https://www.sentencingproject.org/criminal-justicefacts/

${ }^{25}$ Melinda D. Anderson, How Mass Incarceration Pushes Black Children Further Behind in School, THE ATLANTIC (January 16, 2017), https://www.theatlantic.com/education/archive/2017/01/how-mass-incarceration-pushes-blackchildren-further-behind-in-school/513161/

${ }^{26}$ Ashley Nellis, Ph.D., The Color of Justice: Racial and Ethnic Disparity in State Prisons, THE SENTENCING PROJECT, (2016), https://www.sentencingproject.org/publications/color-of-justice-racial-and-ethnic-disparity-instate-prisons/
} 
A primeira possível explicação para o encarceramento desproporcional de pessoas de cor é que nós estamos diante de uma ilusão de ótica. Quando observamos o que parece ser desigualdade racial, na verdade o que vemos é a influência da pobreza, não da raça. Pessoas pobres simplesmente não passam tão bem pelo nosso sistema de justiça criminal quanto pessoas abastadas. Acontece, apenas, que as taxas de pobreza entre negros e latinos são consideravelmente mais altas do que entre brancos. Desde o período de 2007 até 2011, por exemplo, 25,8\% dos negros e 23,2\% dos hispânicos e latinos eram pobres, comparados a 11,6\% dos brancos não-hispânicos e $11,7 \%$ de asiáticos ${ }^{27}$. Estes são dados do governo americano.

Para considerar com seriedade esta explicação, nós devemos observar diversas dimensões possíveis. Em primeiro lugar, o argumento usado é que as pessoas pobres cometem mais crimes do que as ricas, especialmente crimes contra a propriedade. Isto é intuitivamente plausível. No entanto, se levarmos em conta a pirataria de softwares, as fraudes financeiras, os crimes ambientais e outros crimes similares, este argumento provavelmente não se sustenta. Além disso, em termos do montante dos valores em jogo, os crimes contra a propriedade cometidos pelos pobres realmente representam uma ninharia ${ }^{28}$.

É possível, ademais, que as pessoas pobres cometam mais crimes de rua e mais crimes violentos que impactam a segurança pública, aumentando os medos da comunidade e, portanto, atraindo mais atenção policial do que os crimes financeiros, os quais podem ocorrer com o apertar de um botão.

Isto poderia ser verdade. Existe evidência estatística de que os homens afro-americanos, particularmente os jovens, se envolvem desproporcionalmente em crimes violentos ${ }^{29}$. Ademais, numa pequena variação, talvez as pessoas pobres cometam mais crimes em público e, portanto, sejam mais facilmente apreendidas pela polícia. Suas ofensas são simplesmente mais visíveis. O advogado branco e rico que cheira cocaína em seu escritório, ao invés de fazê-lo na esquina, está

\footnotetext{
${ }^{27}$ Suzanne Macartney, et al., American Community Survey Briefs, Poverty Rates for Selected Detailed Race and Hispanic Groups by State and Place: 2007-2011, UNITED STATES CENSUS BUREAU (February 2013), https://www.census.gov/prod/2013pubs/acsbr11-17.pdf

${ }^{28} 2016$ Crime in the United States, FBI:UCR, https://ucr.fbi.gov/crime-in-the-u.s/2016/crime-in-the-u.s.-2016/topicpages/tables/table-21

${ }^{29}$ Alexia Copper, et al., Homicide Trends in the United States, 1980-2008, U.S. DEPARTMENT OF JUSTICE (November 2011) https://www.bjs.gov/content/pub/pdf/htus8008.pdf
} 
menos vulnerável a ser preso. As pessoas pobres vivendo em apartamentos apertados, cujas vidas sociais são conduzidas substancialmente nas ruas, são simplesmente os frutos pendurados nos galhos mais baixos das árvores ${ }^{30}$, mais vulneráveis à atuação policial. Isto também deve ser considerado.

Por último, quando homens ricos e pobres enfrentam processos na justiça, o fazem a partir de recursos amplamente desiguais. Este problema, em si mesmo, merece ser explorado para além do escopo deste artigo. No entanto, vou elaborá-lo brevemente. Pessoas ricas são capazes de minimizar ou escapar completamente de punição através de uma variedade de recursos. Um caso que parece demonstrá-lo foi o julgamento, em 1995, de O.J. Simpson ${ }^{31}$. Este jogador de futebol americano, uma estrela nos Estados Unidos, foi preso e processado pelo assassinato de um jovem homem, juntamente com a ex-esposa de Simpson. As provas pareciam convincentes de que ele, de fato, era culpado. No entanto, ele contratou uma equipe brilhante de $\operatorname{advogados}^{32}$, e foi considerado inocente pelo júri. Esta foi uma situação na qual um homem afroamericano que, casualmente, era dotado de grandes recursos, inclusive econômicos, foi capaz de escapar de punição em decorrência disto.

Apesar deste exemplo, existem vastas evidências de que, se você tirara classe social ou as condições econômicas da equação, a raça continua a ser um fator. Isto é verdade para o chamado "novo policiamento" ou "policiamento de comunidade", com seu uso de estatísticas para dirigir recursos policiais e sua ênfase em intervenções agressivas sobre crimes banais e perturbações triviais da ordem ${ }^{33}$. A raça também parece impactar sobre o exercício procedimental da discricionariedade, por exemplo, em como promotores retiram as acusações ou oferecem acordos favoráveis aos réus ${ }^{34}$.

\footnotetext{
${ }^{30}$ [N.T.] Os frutos pendurados, hanging fruit no original em inglês, remetem à música Strange Fruit, na qual a cantora de jazz Billie Holiday faz referência a um homem negro enforcado em uma árvore de sua vizinhança, no contexto americano de racismo explícito segregacionista, onde esta prática era comum.

${ }^{31}$ Isto ocorreu na metade da década de 1990.

32 Incluindo meu ex-professor de Processo Criminal de Harvard.

${ }^{33}$ Racism Creates Barriers to Effective Community Policing,40 S. Ill. U. L.J. 501 (2015-2016); Community Oriented Policing Services, U.S. DEPARTMENT OF JUSTICE, https://cops.usdoj.gov/Default.asp?Item=2558

${ }^{34}$ Em 1991, o jornal San Jose Mercury News revisou cerca de 700 mil casos criminais da Califórnia, ocorridos entre 1981 e 1990, e revelou disparidades raciais estatisticamente relevantes em diferentes estágios do processo de justiça criminal. Estas descobertas incluem os seguintes dados: seis por cento dos brancos, comparados a quatro por cento dos não-brancos, ganharam casos onde os promotores retiraram por completo as acusações, seguindo o que é
} 
Em resumo: apesar de existir evidência para corroborar que a pobreza, e não a raça, gera resultados desiguais na justiça criminal, e que negros e latinos sofrem desproporcionalmente porque são pobres e não por uma questão de raça, existe alguma evidência contrária que desafia esta ideia.

\section{Próxima Hipótese: Guerra às Drogas}

A próxima possível explicação para as desigualdades raciais no sistema de justiça criminal é que, na verdade, estamos olhando para os efeitos da Guerra às Drogas ${ }^{35}$ e que, como no primeiro caso, a aparência de desigualdade racial é um tipo de ilusão de ótica. Os negros foram varridos pelo sistema de justiça criminal em números desproporcionais devido ao seu uso irresponsável de drogas. De fato, a epidemia de crack varreu o cenário urbano americano nas décadas de 1980 e 1990 e a preocupação com as drogas levaram a sentenças judiciais repressivas cujo tempo mínimo obrigatório era bem extenso, ao que se soma uma série de outros problemas $\operatorname{associados}^{36}$. Conflitos por território entre gangues do tráfico, em cidades como a capital Washington e Oakland, na Califórnia, as tornaram parecidas com zonas de guerra ${ }^{37}$.

O principal problema com esta explicação é que as taxas de uso de drogas nos Estados Unidos não eram significativamente diferentes entre raças. Na verdade, as taxas mais altas de

considerado o "interesse da justiça". Da mesma forma, a $20 \%$ dos réus brancos foi dada a opção de participar de um programa de reabilitação fora do cárcere, em comparação a 14\% dos negros em situação similar e 11\% dos latinos e hispânicos. Mercury News Report, Plea Bargaining Favors Whites, as Blacks, Hispanics Pay Price, SAN JoSE MERCURY News (December 8, 1991), p. 1A; BesikiKutateladze, et al., Race and Prosecution in Manhattan, VERA INSTITUTEOF JUSTICE (July 2014), https://storage.googleapis.com/vera-web-assets/downloads/Publications/race-andprosecution-in-manhattan/legacy downloads/race-and-prosecution-manhattan-summary.pdf (um estudo similar foi conduzido entre 2010 e 2011 na cidade de Nova Iorque; "a raça permaneceu um fator significativo estatisticamente independente na maioria das variantes examinadas como parte da pesquisa").

${ }^{35}$ Referência à "Guerra contra as Drogas" anunciada por George Bush Sr. ao final da década de 1980.

${ }^{36}$ Cf. Alexander, supra, The New Jim Crow, pages 53-54.

${ }^{37}$ United States Attorneys and Attorney General of the United States, Drug Trafficking: A Report to the President of the United States, U.S. DEPARTMENT OF JUSTICE (1989)

https://catalog.hathitrust.org/Record/002490385; cf. Alexander, supra, The New Jim Crow, pages 74-78. 
consumo estavam entre adolescentes e profissionais brancos, incluindo o consumo de crack, esta droga que se supunha particularmente perigosa e viciante ${ }^{38}$.

Se este fosse o caso, talvez a aparência de desigualdade racial pudesse ser uma ramificação de crimes associados, especialmente os violentos, como parte da epidemia de crack? $\mathrm{O}$ argumento aqui seria que, se os afro-americanos consumissem drogas na privacidade de seus lares e escritórios, como fazem os profissionais brancos, e pagassem por seus vícios com seu salário ao invés de sustentá-lo com roubos e crimes de rua, então as taxas de encarceramento poderiam nunca ter se tornado tão desiguais.

Assim como na primeira hipótese, a evidência é inequívoca e existe razão para acreditar que pode haver alguma verdade aqui. No entanto, é preciso reconhecer que a própria ideia de uma guerra, uma guerra interna, possui tonalidades raciais desde o princípio.

Consideremos um exemplo mais contemporâneo - nossa resposta nos últimos anos, incluindoo último ciclo eleitoral de 2016, à chamada crise de opioides - uma questão que afligiu muitas comunidades rurais brancas recentemente nos Estados Unidos. A crise de opioides se tornou um grande assunto em nosso debate sobre saúde, diante da qual, muitos políticos conservadores republicanos defenderam o financiamento do sistema de saúde para lutar contra esta crise na saúde pública. Em outras palavras, quando muitos americanos brancos estão morrendo de overdose, nós sofremos uma "crise de saúde pública". Quando nós aparentemente tivemos uma comunidade afro-americana afligida por uma epidemia de drogas, o resultado foi uma demanda por guerra.

\section{V. Última Hipótese: o Encarceramento em Massa é o Novo Jim Crow}

Michele Alexander, uma Professora Titular de Direito nos Estados Unidos, autora do livro chamado The New Jim Crow: Mass Incarceration in na Age of Colorblindness ${ }^{39}$, argumenta que o encarceramento negro e o status de egresso do sistema prisional se tornaram os novos

\footnotetext{
${ }^{38} \mathrm{Cf}$. Alexander, supra, The New Jim Crow, page 99.
}

${ }^{39} \mathrm{Id}$. 
veículos para a manutenção do privilégio racial branco. O racismo, na era da cegueira de cor, nunca desapareceu verdadeiramente. Ele foi apenas forçado a submergir e se tornar implícito. E apesar de aparentemente nos depararmos com uma nova atitude na era Trump, na qual o racismo e a intolerância novamente se aproximaram da superfície, "a cegueira de cor" continua a prevalecer como uma ética pública.

Como ainda não é possível, para os políticos, falar abertamente em termos raciais, as imagens raciais são formadas em código. Por exemplo, na eleição presidencial de 1988, Willie Horton, um homem negro que foi condenado por estupro e homicídio após fugir de um programa licença condicional para trabalho ${ }^{40}$, foi o foco de propaganda eleitoral. O então candidato republicano, George Bush Sr., usou propaganda televisiva para insinuar que se o seu oponente, o democrata Michael Dukakis, fosse eleito, poderiam haver mais "Willie Hortons" à espreita nas ruas porque Dukakis aprovava o programa de licença condicional. A propaganda fazia um apelo implícito ao viés racial e foi um fator significativo para que Dukakis perdesse a eleição. Mais recentemente, a descrição feita pelo presidente Trump sobre os membros da gangue MS-13, chamando-os de “animais", aparenta um jogo implícito de viés racial contra latinos, dessa forma insultando todos os imigrantes latinos e hispânicos como se fossem todos criminosos e membros de gangues ${ }^{41}$.

A hipótese da Professora Alexander poderia estar correta? Como a justiça criminal se tornou o principal meio de impor diferenças raciais e manter os privilégios dos brancos?

Através do fenômeno do encarceramento em massa. Nos últimos trinta anos, os Estados Unidos se tornaram um Estado carcerário ou prisional. Durante este período, a quantidade de pessoas que nós mantemos atrás das grades dobrou ${ }^{42}$. Previamente, nós tivemos taxas muito altas de encarceramento em comparação a outras nações, mas agora nós somos os líderes mundiais em

\footnotetext{
${ }^{40}$ Um programa de sentenças alternativas que permite aos juízes liberar o condenado para trabalhar durante o cumprimento de seu período de encarceramento.

${ }^{41}$ Geobeats, Trump Accuses Nanci Pelosi of Protecting MS-13 Gang Members, AOL. (June 16, 2018, 3:27pm), https://www.aol.com/article/news/2018/06/16/trump-accuses-nancy-pelosi-of-protecting-ms-13-gangmembers/23460730/

${ }^{42}$ Trends in U.S. Corrections, THE SENTENCING PROJECT, (2016), https://sentencingproject.org/wpcontent/uploads/2016/01/Trends-in-US-Corrections.pdf
} 
encarceramento, com 2,2 milhões de pessoas atrás das grades ${ }^{43}$. Enquanto nós temos apenas cinco por cento da população mundial, abrigamos um quarto de todas as pessoas aprisionadas globalmente ${ }^{44}$. Nós temos proporcionalmente seis vezes o número de prisioneiros confinados atrás das grades que a China, a qual geralmente se considera ter um sistema penal severo ${ }^{45}$.

Enquanto isso, as taxas de crimes graves, especialmente crimes violentos, caíram ${ }^{46}$. Por que eu digo 'enquanto isso'? Não seria esta queda um resultado do encarceramento em massa, o qual está, afinal, alcançando sua meta de nos trazer mais segurança? Nós devemos considerar, entretanto, a variabilidade entre os estados. Nem todos os estados recorreram ao encarceramento em massa, e alguns estados, aqueles com menores taxas de encarceramento, obtiveram o maior declínio nas estatísticas criminais ${ }^{47}$. Portanto, não está de todo claro que o declínio foi causado pelo encarceramento. Ele pode ser um fator, mas não está claro se é um grande fator, e poderia ser meramente um dos fatores minoritários a influenciar nestas mudanças. Outros fatores poderiam ser mudanças demográficas, sentenças mais longas, mudanças em práticas policiais como o "policiamento de pontos quentes" que, a longo prazo, as altas taxas de encarceramento, depois da queda inicial, levaram as estatísticas criminais a subir novamente ${ }^{49}$. Um fator chave é que a grande maioria dos nossos 2,2

\footnotetext{
${ }^{43} \mathrm{Id}$.

${ }^{44}$ Michelle Ye Hee Lee, Does the United States Really Have 5 Percent of the World's Population and One Quarter of the World's Prisons?, THE WASHINGTON POST (April 30, 2015), https://www.washingtonpost.com/news/factchecker/wp/2015/04/30/does-the-united-states-really-have-five-percent-of-worlds-population-and-one-quarter-ofthe-worlds-prisoners/?utm_term=.bc6eb090d791

${ }^{45}$ Trends in U.S. Corrections, supra, THE SENTENCING PROJECT, (2016).

${ }^{46}$ John Gramlich, 5 Trends About Crime in the U.S., THE PEW RESEARCH CENTER (January 30, 2018), http://www.pewresearch.org/fact-tank/2018/01/30/5-facts-about-crime-in-the-u-s/

${ }^{47} \mathrm{Id}$.

${ }^{48}$ Uma estratégia que envolve o direcionamento de atividades e recursos para aqueles lugares onde o crime é mais concentrado. Convergir recursos e atividades em "zonas quentes" tem como objetivo prevenir o crime nestas áreas específicas, e potencialmente reduzir as taxas de criminalidade, de uma maneira geral, numa área geograficamente mais ampla.

${ }^{49}$ The Prison Paradox, VERA InstiTUTE OF JUSTICE (July, 2017), https://www.vera.org/publications/for-the-recordprison-paradox-incarceration-not-safer
} 
milhões de indivíduos encarcerados são infratores não-violentos, segundo a legislação contra drogas ${ }^{50}$.

Em 2005, por exemplo, quatro em cada cinco detenções se deram pela simples posse de maconha e apenas uma em cada cinco pela sua venda ${ }^{51}$. Já entre 1990 e 2009, as detenções por posse de drogas aumentaram oitenta por cento ${ }^{52}$.

Você pode se perguntar: como colocar cerca de 1,3 milhões, ou sessenta por cento de 2,2 milhões, de pessoas de cor atrás das grades mantêm os privilégios dos brancos? Isto faz algum sentido? Afinal de contas, negros e latinos juntos somam, nos Estados Unidos, 100 milhões de pessoas $^{53}$. Este parece um número relativamente trivial, se o verdadeiro objetivo é manter a supremacia branca.

Existem diversas respostas para isso.

A primeira delas é que não é suficiente contabilizar apenas as pessoas que estão na cadeia. Existem muitas outras sob controle do sistema penal, em partícula nos casos de liberdade condicional ou de suspensão condicional do processo ${ }^{54}$. Este é um período no qual a pessoa não está sob custódia, vive na comunidade, mas ainda está sob ameaça de retornar à custódia se as condições de sua liberdade condicional forem violadas. Existem aproximadamente sete milhões de pessoas nos Estados Unidos sob esta supervisão correcional ${ }^{55}$. Apesar da liberdade condicional não ser tão disruptiva para a vida quanto o encarceramento, ela ainda envolve muitas limitações sobre as liberdades individuais. As pessoas que estão em liberdade condicional devem frequentemente se reportar a oficiais de condicional, elas podem precisar se submeter a exames toxicológicos e a programas de aconselhamento, são proibidas de se mudar para procurar

\footnotetext{
${ }^{50}$ Trends in U.S. Corrections, supra, THE SENTENCING PROJECT, (2016).

${ }^{51}$ Alexander, supra, The New Jim Crow, página 60.

${ }^{52}$ Howard N. Snyder, Ph.D., Arrest in the United States, 1990-2010, U.S. DEPARTMENT OF JUSTICE (October, 2012), https://www.bjs.gov/content/pub/pdf/aus9010.pdf

${ }^{53}$ United States Census, Population Estimates for the U.S. as of July 1, 2017, https://www.census.gov/quickfacts/fact/table/US/PST045217\#viewtop

54 [RT] parole: liberdade condicional, após cumprir parte da pena; probation: suspensão condicional do processo, antes da condenação, sursis.

${ }^{55}$ Trends in U.S. Corrections, supra, THE SENTENCING PROJECT, (2016).
} 
emprego, etc. Existem muitas limitações da liberdade, muitas das quais são chamadas "condições de busca", o que significa que elas e/ou suas casas e bens podem ser revistados sem nenhuma justificativa, a qualquer hora do dia ou da noite, e, portanto, estão sujeitas a serem novamente detidas.

Se você olhar apenas para a quantidade de pessoas na cadeia, isso não inclui aquelas com status de ex-presidiários e à privação de direitos frequentemente associada a este status. Por exemplo, uma pessoa condenada não pode concorrer a programas federais de habitação; muitos empregadores não estão dispostos a contratar pessoas com uma ficha criminal; além disso, estudos estimaram que o impacto em rede do status de condenado corresponde a uma redução de $40 \%$ na renda do indivíduo ao longo da vida ${ }^{56}$. Além disso, condenados não podem se candidatar a empréstimos estudantis e seus direitos eleitorais podem ser suspensos pelos governos estaduais $^{57}$. Na verdade, em 2016, 23 estados suspenderam os direitos eleitorais de, ao menos, cinco por cento dos adultos afro-americanos com idade para votar ${ }^{58}$. Em alguns estados, esse número foi superior a vinte por cento, como por exemplo no estado da Flórida ${ }^{59}$. A nível nacional, existem 6,1 milhões de pessoas cujos direitos foram suspensos ${ }^{60}$.

É digno de nota que estas leis foram instituídas principalmente durante a Era Jim Crow e com o propósito explícito de marginalizar afro-americanos. Considere esta afirmação de um político branco do estado de Virgínia, em 1902, em apoio ao plano de reescrever a Constituição do estado de Virgínia de modo a "eliminar o escurecimento ${ }^{61}$ como um fator político neste

\footnotetext{
${ }^{56}$ Dr. Bruce Western, et al., Collateral Costs: Incarceration's Effect on Economic Mobility, page 11, THE PEW CHARITABLE TRUSTS (2010), http://www.pewtrusts.org/ /media/legacy/uploadedfiles/pcs_assets/2010/collateralcosts1pdf.pdf

57 [RT] Disenfranchisement - privado de algum direito ou privilégio, especialmente do direito de votar ${ }^{58}$ Cf Christopher Uggen, et al., 6 Million Lost Voters: State Level Estimates of Felony Disenfranchisement, 2016, THE SENTENCING PROJECT (October 6, 2016), https://www.sentencingproject.org/publications/6-million-lost-votersstate-level-estimates-felony-disenfranchisement-2016/

${ }^{59} \mathrm{Id}$.

${ }^{60}$. Trends in U.S. Corrections, supra, THE SENTENCING PROJECT, (2016).

${ }^{61}[\mathrm{RT}]$ "Eliminate the Darkey" no original em inglês, ou seja, eliminar o escurecimento, corresponde a um termo pejorativo para designar afro-americanos.
} 
estado em menos de cinco anos, para que nenhum país da comunidade britânica de nações tenha que se preocupar com a completa supremacia da raça branca nos assuntos do governo"62.

Olhar apenas para quem está, de fato, encarcerado também negligencia o efeito que se estende sobre as famílias negras. Isto se refere parcialmente ao impacto sobre a família quando um de seus membros é encarcerado, e em parte sobre a pobreza e perturbação da economia familiar. Você perdeu uma pessoa capaz de ganhar um salário e existem custos associados à viagem para visitar familiares encarcerados. Dois sociólogos da Universidade de Villanova argumentaram que milhões de pessoas foram forçadas abaixo da linha da pobreza pelo encarceramento $^{63}$.

O encarceramento também difunde dinâmicas comunitárias nocivas. Presidiários são em sua esmagadora maioria homens, de modo que as proporções entre homens e mulheres nas comunidades são substancialmente desiguais. Na região da Baía de São Francisco, na California $^{64}$, onde eu moro, existem 82 homens afro-americanos para cada cem mulheres afroamericanas ${ }^{65}$. Especialistas em saúde pública perceberam uma correlação entre as crescentes taxas de encarceramento e índices mais altos de gravidez na adolescência, bem como de doenças sexualmente transmissíveis, incluindo HIV. Eles especulam que as mulheres podem ter menos poder de praticar sexo seguro ou de insistir que seus parceiros permaneçam monogâmicos quando existem menos homens que mulheres ${ }^{66}$. Isto coloca os homens numa posição de poder em relação às mulheres, e cônjuges podem sofrer de depressão como consequência disso.

62 Editorial, Mr. McAuliffe's Political, andPrincipled Move, THE WASHINGTON POST (April 23, 2016), https://www.washingtonpost.com/opinions/mr-mcauliffes-political-and-principled-move/2016/04/23/b819128408ca-11e6-b283-e79d81c63c1b_story.html?utm term=.f81cbebe1e69("Os racistas que reescreveram a Constituição do estado de Virgínia em 1902 não ocultaram seus objetivos. Impostos, avaliações de erudição e privação de direitos eleitorais para presidiários tiveram, todos, cobertura constitucional.”).

${ }^{63}$ H. DeFina, Robert \& Hannon, Lance, The Impact of Mass Incarceration on Poverty, 4 Crime \& Delinquency 59 (2009), https://www.researchgate.net/publication/228199876 The_Impact_of_Mass_Incarceration_on_Poverty ${ }^{64}$ [NT] Em inglês, Bay Area.

${ }^{65}$ The Lowdown, MAP: Why Black Women Outnumber Black Men in the Bay Area and Beyond, KQED INC. (2018), https://www.kqed.org/lowdown/20819/why-black-women-significantly-outnumber-black-men-in-the-bay-area

${ }^{66}$ James C. Thomas, PhD, MPH, et al., Incarceration as Forced Migration: Effects on Selected Community Health Outcomes, 98 Am J Public HeAlth (Suppl 1): S181-S184 (September 2008), https://www.ncbi.nlm.nih.gov/pmc/articles/PMC2518603/ 
Existe uma série de estudos que mostra como filhos de pessoas que foram encarceradas são mais propensas a passar por isso. Garotos deixados sem pai com frequência se tornam mais fisicamente agressivos ou exibem problemas socioemocionais ${ }^{67}$. Uma em cada nove crianças afro-americanas têm um de seus pais na cadeia, enquanto o mesmo acontece para uma em cada 28 crianças latinas ou hispânicas e uma em cada 57 crianças brancas ${ }^{68}$. Dessa forma, o encarceramento pode se tornar uma dinâmica que se autoperpetua no futuro.

Agora a principal questão não é necessariamente que réus negros inocentes sejam conduzidos por um sistema de justiça alimentado por brancos racistas. A desigualdade, ao invés disso, está no fato de que pessoas brancas, que usam drogas em proporções similares a pessoas de cor, simplesmente não são presas. Isto é injusto porque a população branca é muito maior do que a negra em termos de números absolutos.

Agora nós chegamos à parte difícil desta hipótese. Se este é, realmente, o novo dispositivo para sustentar a supremacia branca, quem a está dirigindo? Existe algum grupo de racistas poderosos que deliberadamente manipulam o sistema de justiça criminal e realizam o encarceramento em massa para estes fins? Nós podemos ter racismo sem racistas?

Esta é uma questão difícil. Existem evidências crescentes, o que certamente se tornou mais aparente desde nossa última eleição presidencial e de suas repercussões, que traços de racismo ainda existem, os quais nunca desapareceram, mas simplesmente foram deixados de lado pela sociedade polida e pelo discurso da elite. Em outras palavras, os racistas continuam lá fora, eles apenas sabem quando se calar.

\section{O que eles ganham com tudo isso? Qual é a forma de benefício branco?}

Uma expressão que resume parte desta questão é "complexo prisional industrial". Me refiro aqui à construção e administração das prisões. A maioria das prisões construídas nas últimas décadas são localizadas em comunidades rurais, as quais sofreram economicamente de

\footnotetext{
${ }^{67}$ Sara McLanahan, et al., The Causal Effect of Father's Absence, ANNu ReV Sociol (July 2013), https://www.ncbi.nlm.nih.gov/pmc/articles/PMC3904543/

${ }^{68}$ Western, et al., supra, Collateral Costs: Incarceration's Effect on Economic Mobility, (2010).
} 
muitas formas na era pós-industrial. Este foi um dos poucos pontos de sucesso econômico para estas comunidades. Isto pode parecer demasiado conspiratório para alguns, no entanto, outros teriam uma visão mais matizada de sutilezas de agência neste processo.

Vamos olhar novamente para o exemplo de Willie Horton. O que estava acontecendo ali? Nosso candidato presidencial àquela época era George Bush Sr. Ele era racista? Eu nunca tive essa percepção, nem de seu filho, que empregou pessoas de cor para desempenhar poderosos papéis na administração, como Colin Powell, que serviu como primeiro Secretário de Estado de Bush; Condoleezza Rice, a segunda Secretária de Estado; e Alberto Gonzalez, que serviu como Procurador Geral da União.

É possível, entretanto, que as pessoas que criaram estas propagandas para as eleições de 1988 não soubessem das suas implicações? Isto parece improvável, considerando como essa propaganda é cuidadosa e deliberadamente organizada. Portanto, uma possibilidade é que elites, as quais podem não ser racistas, não obstante manipulem o sentimento popular entre as classes menos favorecidas para obter vantagens políticas. Isso pode ter sido a realidade, particularmente, dentro do Partido Republicano, desde muito antes de Trump se tornar presidente, inclusive no que diz respeito ao encarceramento em massa. Apesar disto, a manipulação deliberada das elites sobre o sentimento popular entre os brancos de classes desfavorecidas ficou perfeitamente evidente na campanha de Trump.

Nos Estados Unidos de hoje, dentro do direcionamento neoliberal que tomamos, nós optamos pelo uso de recursos externos, ou pela privatização, da responsabilidade sobre a supervisão de pessoas em sursis, cujo processo foi suspenso. Assim, esta condição probatória frequentemente deixou de ser gerenciada pelos oficiais de justiça ou outros funcionários públicos, e foi passada para corporações privadas. Além disso, os governos locais e as forças de segurança passaram a se motivar pelo lucro e têm crescentemente financiado suas próprias atividades, se projetando através de multas, dos custos do processo e do confisco de bens civis ${ }^{69}$.

\footnotetext{
${ }^{69}$ [RT $\}$ O confisco de bens civis (civil asset forfeiture) é um procedimento não-criminal que permite às autoridades, aos tribunais, tomar bens de civis: tais como dinheiro, carros, ou qualquer propriedade que eles acreditam estar marcada pelo crime ou ser fruto de crime, tomando posse destes mesmo antes de comprovada a culpa do indivíduo, seguindo padrões comprobatórios inferiores àqueles requeridos num procedimento judicial criminal.
} 
Por exemplo, em 2015, a prefeitura da cidade de Ferguson, no estado de Missouri, onde ocorreu o assassinato de Michael Brown e nasceu o movimento Vidas Negras $\operatorname{Importam}^{70}$,antecipou a informação de que um terço de toda a sua renda anual seria coletada através de fianças, multas por infrações de trânsito e por outros crimes de menor potencial ofensivo $^{71}$. Os Estados Unidos justificam isso apelando para a consciência moral de que não há nada de errado em forçar os culpados a assumir os custos de seus próprios erros. Se as pessoas precisam pagar pelos custos dos processos judiciais ou por fianças, ou pelos exames toxicológicos e outros custos da liberdade condicional, isso é consequência de seu próprio mau comportamento e, em tempos de recursos escassos, não há nada de errado com isso.

O encarceramento em massa também promove a manutenção da segregação ${ }^{72}$ de diferentes formas. Não é mais permitido por lei praticar a segregação racial, no entanto, a supervisão penal essencialmente mantém as pessoas no seu lugar, e eu quero dizer isso tanto no sentido figurado quanto no literal. Isso os mantém presos, social e espacialmente, no lugar de onde vieram.

Também é possível que o encarceramento em massa não seja, exatamente, uma estratégia consciente de ninguém. Ao invés disso, permite espaço para sentimentos subconscientes de medo e hostilidade contra negros e latinos, e oferece uma expressão aceitável daqueles sentimentos, nesta era da cegueira de cor. Ao mesmo tempo, tem o efeito de preservar os privilégios dos brancos.

Uma possibilidade alternativa é que os negros encarcerados que não vemos, não nos preocupam, e a forma contemporânea do racismo americano se parece mais com indiferença ou falta de empatia do que com a completa hostilidade. Enquanto o encarceramento em massa pode não ser totalmente eficaz em preservar o privilégio branco, esta pode ser a melhor alternativa disponível diante das circunstâncias sociais e políticas que prevalecem. Isto se manifesta como uma falsa consciência,devido à distância entre as crenças subjetivas e a verdadeira função social

\footnotetext{
${ }^{70}$ [N.T.] Black Lives Matter.

${ }^{71}$ DOJ Report on Ferguson Police Department, ST. LouIs PosT -DisPATCH (March 4, 2015), https://www.stltoday.com/news/multimedia/special/pdf-department-of-justice-s-report-on-ferguson-policedepartment/html_8b689eda-e822-5607-bbaa-b87b0e22d90b.html?2

${ }^{72}$ A separação substancial de comunidades, entre comunidades afro-americanas e comunidades brancas.
} 
de uma instituição ou de um conjunto de práticas. Além disso, é plausível que o encarceramento em massa tenha produzido a maioria das vantagens da supremacia branca sem a bagagem moral e ideológica das estruturas e das ideologias anteriores, abertamente racistas. Em outras palavras, podemos, sim, ter tudo ao mesmo tempo.

Por que eu considero esta hipótese persuasiva, e porque a considero mais persuasiva que as outras?

Primeiro, o instinto me diz que as crenças culturais profundamente enraizadas, como o racismo, são muito resistentes à mudança. O mesmo é verdade para as práticas sociais, econômicas e políticas. Não me parece confiável acreditar que, diante da mera aprovação de leis, as atitudes mudem.

Nós também temos o precedente histórico da transformação de um regime racial, a escravidão, para outra forma, a Era Jim Crow. Isto não significa um mesmo produto numa nova embalagem, mas aconteceu uma mudança genuína e possivelmente um progresso. Existe um consenso geral de que, se você estudar a situação, por mais repulsivas e terríveis que as chamadas Leis Jim Crow fossem, elas eram melhores se comparadas à escravidão.

Da mesma forma, o encarceramento em massa pode ser uma pequena melhora em comparação à Era Jim Crow. Afinal de contas, existem sinais de progresso, como a eleição de Barak Obama, ou a ascensão de um grande número de negros para o status de classe média, bem como a proeminência dos afro-americanos no entretenimento: tudo isso indica que os negros adquiriram maior poder político. Estas mudanças ou conquistas em direção à igualdade racial não são incompatíveis com a hipótese do encarceramento em massa. Na verdade, a aparência de progresso racial, para alguns, pode contribuir para mascarar a continuidade das desigualdades, na visão de muitos outros.

\section{Conclusão}

Se o encarceramento em massa de negros e latinos é a nova maneira pela qual a supremacia branca é verdadeiramente sustentada nos Estados Unidos, quais são as implicações desta conclusão? O que nós podemos fazer? 
Primeiramente, vale lembrar que o sistema de justiça criminal é onde o chicote encontra a carne. A liberdade humana está em jogo, e aprendemos a sustentá-la como mais fundamental do que qualquer coisa. No entanto, isto não é uma preocupação apenas para as pessoas que sofrem diretamente essa dor. A aparência de injustiça racial na polícia e no sistema de justiça criminal é prejudicial à sociedade americana, e ao nosso sistema legal como um todo. As explosões de revoltas e violência racial frequentemente associadas com percepções de vereditos injustos em casos criminais, ou em casos contra a polícia, são a melhor prova disso. Por exemplo, após o julgamento dos abusadores ${ }^{73}$ de Rodney King, em 1992, as ruas de Los Angeles explodiram em revolta, e depois de liberado o leve veredicto para o policial que atirou em Oscar Grant em $2010^{74}$, Oakland protestou violentamente. Em outras palavras, isto é um problema, que nós ignoramos por nossa própria conta e risco.

Então, o que podemos fazer?

Em primeiro lugar, este assunto precisa ser trazido à luz. Nós precisamos falar sobre ele, torná-lo público, fazer dele uma parte do debate de políticas públicas. É também apropriado, como a Professora Alexander argumentou em seu livro, reorientar o foco do movimento pelos direitos civis das ações afirmativas para uma justiça igualitária nos procedimentos criminais. Isto não tem sido prioridade para organizações como a Associação Nacional para o Avanço de Pessoas de Cor (NAACP) ${ }^{75}$, a qual foi uma força motriz importante no movimento dos direitos civis nas décadas de 1950 e 1960. A União Americana pelas Liberdades Civis (ACLU) ${ }^{76}$, e outras organizações de interesse público que tiveram a missão de defender os direitos civis não se concentraram realmente no assunto, mas deveriam.

Por exemplo, uma das possibilidades com maior potencial seria modificar nosso sistema de fiança ${ }^{77}$. Pessoas ricas podem pagar por uma fiança. Quem pode pagar para sair de custódia possui opções extensamente melhores para navegar no sistema de justiça criminal do que as

\footnotetext{
${ }^{73} \mathrm{Um}$ taxista afro-americano foi filmado enquanto era espancado por quatro policiais em Los Angeles, os quais foram subsequentemente absolvidos.

${ }^{74} \mathrm{Um}$ homem afro-americano de 22 anos de idade foi filmado ao ser morto a tiros, enquanto estava imobilizado no chão por um policial, o qual foi condenado apenas por homicídio involuntário, um crime relativamente leve.

75 [N.T.] National Association for the Advancement of Colored People.

${ }^{76}[$ N.T.] American Union for Civil Liberties.

${ }^{77}$ Fiança é a quantidade de dinheiro que uma pessoa deve pagar ao tribunal para não permanecer detido durante o julgamento de seu caso.
} 
pessoas que não têm. Além disso, uma reforma no sistema de fiança para equalizar, ou seja, tirar o dinheiro da equação e simplesmente não requisitar o um pagamento de fiança antes do julgamento, seria um avanço incrível.

Nós também precisamos tomar medidas para eliminar a discriminação contra expresidiários e facilitar o seu reingresso na sociedade como, por exemplo, descontos nos impostos para empregadores que os contratem. Além disso, é claro, rapidamente restaurar o direito ao voto logo após o cumprimento de uma sentença criminal, ou mesmo eliminar a suspensão de direitos eleitorais por completo.

Nós também precisamos procurar alianças onde podemos, sem esperar simplesmente extinguir o racismo consciente a curto prazo. Nós podemos encontrar aliados, por exemplo, entre aqueles dispostos a reavaliar o sistema de justiça criminal sob outros parâmetros ou sob diferentes perspectivas.

Por exemplo, há um movimento que começou vinte ou vinte e cinco anos atrás, chamado “projetos de inocência”. Estes são esforços, com frequência baseados em Faculdades de Direito e às vezes em ONGs, as quais usam exames de DNA para reverter condenações errôneas. O uso de DNA tem sido extremamente útil como prova conclusiva, mesmo para pessoas sem inclinação a ter empatia pelos criminosos, de que existem muitas condenações erradas no nosso sistema.

Além disso, existem preocupações políticas da direita sobre conservadorismo fiscal, qual seja, o impacto de gastos com o financiamento do encarceramento, o que, por uma preocupação puramente pragmática, é uma questão importante para pessoas que se identificam politicamente com a direita. Eu não vejo motivos para deixar de fazer alianças com pessoas cujas motivações talvez sejam completamente diferentes, mas que podem unir forças em algum esforço conjunto.

Meu país tem muito para compensar, pela forma como se conduziu no mundo para além de nossas fronteiras e, também, por como tem tratado o próprio povo. Isto começa com os indígenas nativos de nossa terra, se estende aos escravos, inclui nossos imigrantes e hoje também as comunidades de pessoas de cor. Do meu ponto de vista, isto não acontece principalmente pelo fracasso de nossos ideais, mas sim por um fracasso em viver segundo nossos ideais. Corrigir esse grave problema, a grande injustiça que está no núcleo de nossa sociedade, ajudaria, portanto, a nos perceber como cidadãos estadunidenses, e nos tornar mais autenticamente quem nós queremos ser. 


\section{Bibliografia}

ACLU. What is Affirmative Action? Disponível em: < https://www.aclu.org/other/whataffirmative-action>.

ACLU. Annual Stop-And-Frisk Numbers.New York, (2002-2017).Disponível em: $<$ https://www.nyclu.org/en/stop-and-frisk-data $>$.

ALEXANDER, Michelle. A Nova Segregação: racismo e encarceramento em massa. São Paulo, Boitempo, 2017.

AOL, Geobeats, Trump Accuses Nanci Pelosi of Protecting MS-13 Gang Members,. (June 16, 2018, 3:27pm). Disponível em;< https://www.aol.com/article/news/2018/06/16/trump-accusesnancy-pelosi-of-protecting-ms-13-gang-members/23460730/> .

ANDERSON, Melinda D. How Mass Incarceration Pushes Black Children Further Behind in School, THE ATLANTIC (January 16, 2017). Disponível em: https://www.theatlantic.com/education/archive/2017/01/how-mass-incarceration-pushesblack-children-further-behind-in-school/513161/.

BESIKIKUTATELADZE, et al., Race and Prosecution in Manhattan, VERA INSTITUTE OF JUSTICE (July 2014). Disponível em: <https://storage.googleapis.com/vera-webassets/downloads/Publications/race-and-prosecution-in-manhattan/legacy_downloads/race-andprosecution-manhattan-summary.pdf $>$.

Caso Apodaca v. Oregon, 406 U.S. 404 (1972)

Caso Johnson v. Louisiana, 406 U.S. 356 (1972).

Caso Washington v. Davis, 426 U.S. 229 (1976).

Caso Williams v. Florida, 399 U.S. 78 (1970).

CasoVillage of Arlington Heights v. Metropolitan Housing Development Corp., 429 U.S. 252 (1977). 
UGGEN, Christopher, et al., 6 Million Lost Voters: State Level Estimates of Felony Disenfranchisement, 2016, THE SENTENCING PROJECT (October 6, 2016). Disponível em: $<$ https://www.sentencingproject.org/publications/6-million-lost-voters-state-level-estimatesfelony-disenfranchisement-2016/>

COPPER Alexia, et al.. Homicide Trends in the United States, 1980-2008, U.S.

DEPARTMENT OF JUSTICE (November 2011). Disponível em: $<$ https://www.bjs.gov/content/pub/pdf/htus8008.pdf $>$.

Criminal Justice Facts, THE SENTENCING PROJECT, (2016), https://www.sentencingproject.org/criminal-justice-facts/

DOJ Report on Ferguson Police Department, ST. LOUIS POST -DISPATCH (March 4, 2015), https://www.stltoday.com/news/multimedia/special/pdf-department-of-justice-s-reporton-ferguson-police-department/html_8b689eda-e822-5607-bbaa-b87b0e22d90b.html?2

Federal Justice Statistics, Bureau of Justice Statistics, 2014. Disponível em: $\langle$ https://www.bjs.gov/content/pub/pdf/fjs1314_sum.pdfe>.

FBI:UCR. Crime in the United States, 2016. Disponível em: $<$ https://ucr.fbi.gov/crime-in-theu.s/2016/crime-in-the-u.s.-2016/topic-pages/tables/table-21>.

FERREIRA, Marco Aurélio Gonçalves. O devido processo legal: um estudo comparado. Rio de Janeiro: Lúmen Juris, 2004.

FINKELMAN, Paul (editor). Statutes on Slavery: The Pamphlet Literature, 2007.

GRAMLICH, John. 5 Trends About Crime in the U.S., THE PEW RESEARCH CENTER (January 30, 2018). Disponível em: $<$ http://www.pewresearch.org/facttank/2018/01/30/5-facts-about-crime-in-the-u-s/ $>$.

H. DEFINA, Robert ; LANCE, Hannon. The Impact of Mass Incarceration on Poverty, 4. Crime \& Delinquency 59 (2009). Disponível em: $<$ https://www.researchgate.net/publication/228199876_The_Impact_of_Mass_Incarceration_ o_Poverty $>$.

HOFFMAN, Jan. Editorial, The Nation; Why a Jury Can Be 12, Even 6, but Not 5, N.Y. TIMES (June 11, 1995). Disponível em: < https://www.nytimes.com/1995/06/11/weekinreview/thenation-why-a-jury-can-be-12-even-6-but-not-5.html $>$.

https://catalog.hathitrust.org/Record/002490385; cf. Alexander, supra, The New Jim Crow, pages 74-78.>.

https://www.census.gov/quickfacts/fact/table/sanfranciscocountycalifornia/PST045217\#viewtop $>$. 
KANT DE LIMA, Roberto. Polícia, justiça e sociedade no brasil: uma abordagem comparativa dos modelos de administração de conflitos no espaço público. Revista de Sociologia e Política, Curitiba - Paraná, v. 1, n.13, p. 23-38, 1999.

LEE, Michelle Ye Hee. Does the United States Really Have 5 Percent of the World's Population and One Quarter of the World's Prisons?, THE WASHINGTON POST (April 30, 2015). Disponível em:https://www.washingtonpost.com/news/fact-checker/wp/2015/04/30/doesthe-united-states-really-have-five-percent-of-worlds-population-and-one-quarter-of-the-worldsprisoners/?utm_term=.bc6eb090d791.

LY, Laura. Oberlin College Cancels Classes to Address Racial Incidents, CNN (March 5, 2013). Disponível em:< https://www.cnn.com/2013/03/04/us/ohio-oberlin-hateincidents/index.html $>$.

MACARTNEY, Suzanne et al. American Community Survey Briefs, Poverty Rates for Selected Detailed Race and Hispanic Groups by State and Place: 2007-2011, UNITED STATES

CENSUS BUREAU (February 2013). Disponível em:

$<$ https://www.census.gov/prod/2013pubs/acsbr11-17.pdf. $>$.

Mercury News Report, Plea Bargaining Favors Whites, as Blacks, Hispanics Pay Price, SAN JOSE MERCURY NEWS (December 8, 1991), p. 1A.

NELLIS, Ashley. Ph.D., The Color of Justice: Racial and Ethnic Disparity in State Prisons, THE SENTENCING PROJECT, (2016). Disponível

em: $<$ https://www.sentencingproject.org/publications/color-of-justice-racial-and-ethnicdisparity-in-state-prisons/>.

Non-Unanimous Jury Convictions Violates Equal Protection Clause, ACLU

OREGON (December, 15 2016). Disponível em: $<$ https://www.aclu-or.org/en/cases/nonunanimous-jury-convictions-violate-equal-protection-clause $>$.

Prosecutors in State Courts. Bureau of Justice Statistics, 2007. Disponível em: $<$ https://www.bjs.gov/content/pub/pdf/psc07st.pdf $>$.

Racism Creates Barriers to Effective Community Policing,40 S. Ill. U. L.J. 501 (2015-2016); Community Oriented Policing Services, U.S. DEPARTMENT OF

JUSTICE, https://cops.usdoj.gov/Default.asp?Item $=2558$

RICE, Thomas D. The Original Jim Crow, New York, (1832). Disponível em

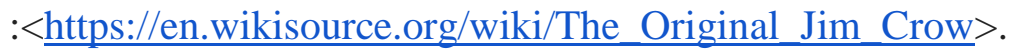

MCLANAHAN Sara, et al., The Causal Effect of Father's Absence, ANNU REV

SOCIOL (July 2013). Disponível

em:< https://www.ncbi.nlm.nih.gov/pmc/articles/PMC3904543/>. 
SNYDER, Howard N. Ph.D., Arrest in the United States, 1990-2010, U.S. DEPARTMENT OF JUSTICE (October, 2012). Disponível em: $<$ https://www.bjs.gov/content/pub/pdf/aus9010.pdf $>$.

The Lowdown, MAP: Why Black Women Outnumber Black Men in the Bay Area and Beyond, KQED INC. (2018). Disponível em:< https://www.kqed.org/lowdown/20819/why-blackwomen-significantly-outnumber-black-men-in-the-bay-area $>$.

VERA INSTITUTE OF JUSTICE. The Prison Paradox, (July, 2017). Disponível em: $<$ https://www.vera.org/publications/for-the-record-prison-paradox-incarceration-not-safer $>$.

THE WASHINGTON POST. Editorial, Mr. McAuliffe's Political, and Principled Move, (April 23, 2016). Disponível em:< https://www.washingtonpost.com/opinions/mr-mcauliffes-politicaland-principled-move/2016/04/23/b8191284-08ca-11e6-b283e79d81c63c1b_story.html?utm_term=.f81cbebe1e69>.

THOMAS, James C. PhD, MPH, et al., Incarceration as Forced Migration: Effects on Selected Community Health Outcomes, 98 AM J PUBLIC HEALTH(Suppl 1): S181-S184 (September 2008). Disponível em:< https://www.ncbi.nlm.nih.gov/pmc/articles/PMC2518603/>.

THOMAS, JD. Law of Slavery in the State of Louisiana, ACCESSIBLE ARCHIVES (August 24, 2011). Disponível em:< http://www.accessible-archives.com/2011/08/law-of-slavery-in-thestate-of-louisiana/>

Trends in U.S. Corrections, THE SENTENCING PROJECT, (2016). Disponível em: $\lfloor$ https://sentencingproject.org/wp-content/uploads/2016/01/Trends-in-US-Corrections.pdf $>$.

United States Attorneys and Attorney General of the United States, Drug Trafficking: A Report to the President of the United States, U.S. DEPARTMENT OF JUSTICE (1989).

United States Census, Population Estimates for the U.S. as of July 1, 2017. Disponível em: <https://www.census.gov/quickfacts/fact/table/US/PST045217\#viewtop>.

WESTERN, Bruce, et al. Collateral Costs: Incarceration's Effect on Economic Mobility, page 11, THE PEW CHARITABLE TRUSTS (2010). Disponível em:

<http://www.pewtrusts.org/ /media/legacy/uploadedfiles/pcs_assets/2010/collateralcosts1pdf.pd $\underline{\mathrm{f}}$. 